\title{
Rat lung cancer induced by malathion and estrogen
}

\author{
C. ECHIBURÚ-CHAU ${ }^{1}$ and G.M. CALAF ${ }^{1,2}$ \\ ${ }^{1}$ Instituto de Alta Investigación, Universidad de Tarapacá, Arica, Chile; ${ }^{2}$ Center for Radiological Research, \\ Columbia University Medical Center, New York, NY, USA
}

Received March 14, 2008; Accepted May 12, 2008

\section{DOI: 10.3892/ijo_00000046}

\begin{abstract}
Lung cancer can originate from exposure to exogenous and endogenous environmental carcinogens. The use of organophosphorus insecticides has significantly increased in agricultural environments and in urban settings. There is evidence that estrogen can increase lung cancer risk in women. The aim of the present study was to analyze morphological and molecular alterations induced by malathion (M) and 17ß-estradiol (E2) in rat lung tissues. There were four groups: saline solution (control) $(100 \mu \mathrm{g} / 100 \mathrm{~g}$ body weight; BW), M (22 mg/100 g BW), E2 (30 $\mu \mathrm{g} / 100 \mathrm{gr}$ BW) and combination of both. The animals were injected over a 5-day period and sacrificed 240 days after treatments and lung tissues were excised and analyzed for morphological alterations. Morphometric analysis indicated that M plus E2treated animals showed a significantly $(\mathrm{P}<0.05)$ higher incidence of parenchyma with alveolar proliferative lesions (PAPL), preneoplastic lesions in bronchiolar epithelium (hyperplasia, metaplasia, carcinoma in situ and invasive carcinoma) and atypical lymphatic morphology (lymphatic cell aggregates; LCA) than M or E2 alone-treated and control animals after 240 days. Molecular biology studies indicated that c-ErbB2 and Rho-A had higher protein expression in M plus E2-treated animals in comparison to control and either M- or E-treated animals. In summary, the combination of $\mathrm{M}$ and E2 sharply induced pathological lesions in lung alveolar parenchyma, bronchiolar epithelia and lymphatic tissues, in comparison to control animals or in animals treated with either substance alone. These results indicated an increase in risk of rodent lung tumor formation by environmental and endogenous substances.
\end{abstract}

\section{Introduction}

Lung cancer is the leading cause of cancer deaths worldwide (1). Cancer may originate from exposure to exogenous and

Correspondence to: Dr Gloria M. Calaf, Instituto de Alta Investigación, Universidad de Tarapacá, Calle Antofagasta no. 1520, Arica, Chile

E-mail: gmc24@columbia.edu

Key words: rat lung cancer, organophosphorous pesticides, malathion, estrogen endogenous environmental carcinogens. Investigations of occupational groups, who often are heavily exposed over long periods of time to certain workplace agents, have provided substantial awareness of the potential carcinogenicity of a number of chemicals and physical agents. Among cancers that are associated with occupational exposures, lung cancer is the most common (2). The use of insecticides, particularly organophosphorus insecticides, such as malathion, has significantly increased, not only in agricultural environments (3-5) but also in residential and in urban settings (6-11).

There has been a 4-fold increase in lung cancer in women over the past 30 years and it has been estimated that this rise will not plateau until 2010 (12). There is substantial evidence that estrogen can increase lung cancer risk in women, as well as increasing the incidence of adenocarcinoma of the breast $(13,14)$, endometrium and ovary $(15)$. Many studies (12-16) have shown that endogenous estrogens (period of time between menarchia and menopause) and exogenous estrogen (estrogen replacement therapy) can play a role in the development of lung cancer in women. It also has been reported that early age at menopause in women (40 years or younger) is associated with a reduced risk of carcinoma of the lung and the use of estrogen replacement therapy associated with a higher risk of this disease (12).

Primary immune responses are often initiated in the lymph node and in other lymphoid tissues (17). Bienenstock et al (18) have described the normal anatomic distribution of lymphoid tissue in the human lung as being along side the bronchial tree, in the interlobular septa and within subpleural nodes. Pulmonary lymphoid lesions encompass a spectrum of inflammatory and reactive lesions (19).

Immunohistochemistry has an expanding role in the diagnosis and management of lung cancer. Thus, molecular techniques are useful to predict disease progression. The Neu proto-oncogene, also known as ErbB2, EGFR-2, or HER2, is a member of a family of transmembrane receptor tyrosine kinases (20). The erbB (Her) family of oncogenes is frequently overexpressed in lung cancer (21). The erbB gene family encodes for growth factor tyrosine kinase receptors that seem to play a role in the autocrine growth of human lung cancers $(22,23)$. The Rho family of proteins is related to the small GTP binding proteins. It is known that Ras family regulate diverse biological processes including gene transcription, cytoskeletal organization, cell proliferation and transformation. Members of the Rho family of small GTPases control the organization of the actin/myosin cytoskeleton, and thus play significant roles in metastasis $(24,25)$. 
Carcinogenesis is thought to be a multistep process consisting of preneoplastic to neoplastic morphological changes that often reflect the progressive changes in genotypic patterns. Very early cancerous morphological changes (preneoplastic lesions) can be a characteristic phenotypical pattern of the progression from normal to malignant tissue in the lung. At the present time, there are no studies which have examined malathion exposure and estrogen status in relation to lung cancer in women (26). Relatively few genes have been shown to directly affect the metastatic phenotype of lung epithelial cells in vivo. Thus, the aim of the present study was to examine the morphological and molecular alterations in lung tissues by the effect of malathion and $17 ß$-estradiol by analyzing lung alveolar parenchyma, bronchiolar epithelia and lymphatic tissues.

\section{Materials and methods}

Experimental design. There were four experimental groups of 39 day-old virgin female Sprague Dawley rats obtained from the Catholic University of Chile (Santiago, Chile). Five animals per group were housed and bred in a barrier animal facility operated in accordance with the standards outlined in Guide for the Care and Use of Laboratory Animals (27). All rats were allowed continuous access to a standard laboratory chow diet (Champion, Santiago, Chile). The animals were injected subcutaneously for 5 days twice a day with: physiological saline solution (controls), $100 \mu \mathrm{g} / 100 \mathrm{~g}$ body weigh (BW); malathion (M) (Fyfanon ${ }^{\mathrm{TM}}$, Cheminova, Denmark), $22 \mathrm{mg} / 100 \mathrm{~g} \mathrm{BW}$; 17ß-estradiol (E2) (Sigma-Aldrich Chemical Co., Milwaukee), $30 \mu \mathrm{g} / 100 \mathrm{gr} \mathrm{BW}$; and combination of $\mathrm{M}$ and E2 (M+E2). The $\mathrm{LD}_{50}$ value for $\mathrm{M}$ was $1,000 \mathrm{mg} / \mathrm{kg} \mathrm{BW}$ which allowed a $100 \%$ survival of animals after a 5-day treatment (28). The doses used in these experiments were one sixth of the $\mathrm{LD}_{50}$ for $\mathrm{M}$, which allowed a $100 \%$ survival of animals after a 5-day treatment period. The animals were sacrificed 240 days after the last injection and the lung tissue were excised and morphologically analyzed. The rats were sacrificed under ether anesthesia and opened by a midline incision from the pubis to the sub-maxillary area to remove several organs to look for tumor formation. Rat lung tissues and tumors were removed and fixed in $10 \%$ neutral buffered formalin for histopathological studies. The lung tissue sections (five slides per sample) were oriented flat and sectioned at $5 \mu \mathrm{m}$ thicknesses, deparaffinized and stained with hematoxylin and eosin and each one was evaluated under a light microscope.

Quantitative analysis of parenchyma alveolar alterations. The measurements of the samples were done with a light binocular microscope ocular with lenses of x10 and x40. Five slides per animal were counted. Each field was identified by the relative grade of proliferative lesions in the lung parenchyma. These relative grades were characterized according to the damage and categorized from 0 to 25 (5- 10- 15-20-25). Normal tissue was 0 value, and 25 was given to the tissue with the highest amount of tissue damaged. The percentage of area $\left(\mu \mathrm{m}^{2}\right)$ of proliferative lesions in lung parenchyma was calculated in the total area of the fields from 0 to $100 \%$ in each sample.
Quantitative analysis of preneoplastic/neoplastic lesions in bronchiolar epithelium. Analysis of preneoplastic and neoplastic lesions present in the bronchiolar epithelium was done with light binocular microscope ocular lenses of $\mathrm{x} 10, \mathrm{x} 40$ and $\mathrm{x} 100$. The classification of the grades found in the bronchiolar epithelia (hyperplasias, neoplasias, carcinoma in situ and invasive carcinoma) and neoplastic lesions were done accordingly to World Health Organization (WHO) grading (29-31). A value from 0 to 8 (0- 1- 2- 4- 8) was given to quantify data. Thus, if there were no preneoplasias present, the value would be 0 ; hyperplasia, 1 ; squamous metaplasia, 2; carcinoma in situ, 4; and invasive carcinoma, 8 .

Quantitative analysis of lymphatic proliferative lesions. Morphometric and computational studies of cell lesions were measured by using an Olympus CX31 (Rochester, NY, USA) light binocular microscope with ocular lenses of x10 and x40 connected with a Motic MCCamera (2.0 megapixel; MC2001 interface). To measure the samples a Motic Image Plus 2.0 ML software was used. The percentage of area $\left(\mu \mathrm{m}^{2}\right)$ of lymphatic proliferative lesions in lung parenchyma was calculated in the total area of 30 fields and expressed as 0 to $100 \%$ in each sample. Pictures of representative images were taken by a Nikon digital camera (COOLPIX 4600; 4 mega pixel, zoom x3).

Immunochemical staining. Protein expression was evaluated by peroxidase immunochemical staining. Tissues were incubated with $1 \% \mathrm{H}_{2} \mathrm{O}_{2}$ in methanol for $30 \mathrm{~min}$, in order to block endogenous peroxidase, washed twice with a buffer solution, and fixed with buffered paraformaldehyde in PBS, $\mathrm{pH}$ 7.4, at room temperature. Subsequently, tissues were then covered with normal horse-serum for $30 \mathrm{~min}$ at room temperature. Cultures were then washed once and incubated with the corresponding antibodies at a 1:500 dilution overnight at $4{ }^{\circ} \mathrm{C}$. The following antibodies used were: ErbB-2 (9G6; sc08; mouse monoclonal) and transforming factor Rho-A (sc418; mouse monoclonal antibody) (all of Biotechnology Inc., Santa Cruz, CA, USA). Protein expression was determined by using the avidin-biotin-horseradish immunoperoxidase peroxidase complex (Standard ABC kit; Vector, Burlingame, CA, USA). The 3, 3c-Diaminobenzidine (DAB) (SigmaAldrich, St. Louis, MO, USA) was used as a chromogen. For negative controls, duplicate samples were immunostained without exposure to the primary antibody or substituted with pre-immune serum. The extent of peroxidase staining was determined by calculating the percentage of positively stained cells in the population (from 0 to $100 \%$ ) and $0,+1$, +2 , and +3 in relation to staining intensity.

Statistical analysis. The morphological data were expressed as the average \pm standard error (SE) of the mean. Comparison between treated groups and controls were made by ANOVA and Dunnet's test, with $\mathrm{P} \leq 0.05$ between groups was considered to be significant. All numerical immunohistochemical data were calculated as means \pm standard error. Statistical analysis was done with the F-test (Randomized Block) and comparisons between groups with the Bonferroni t-test with significance at $\mathrm{P}<0.05$. 


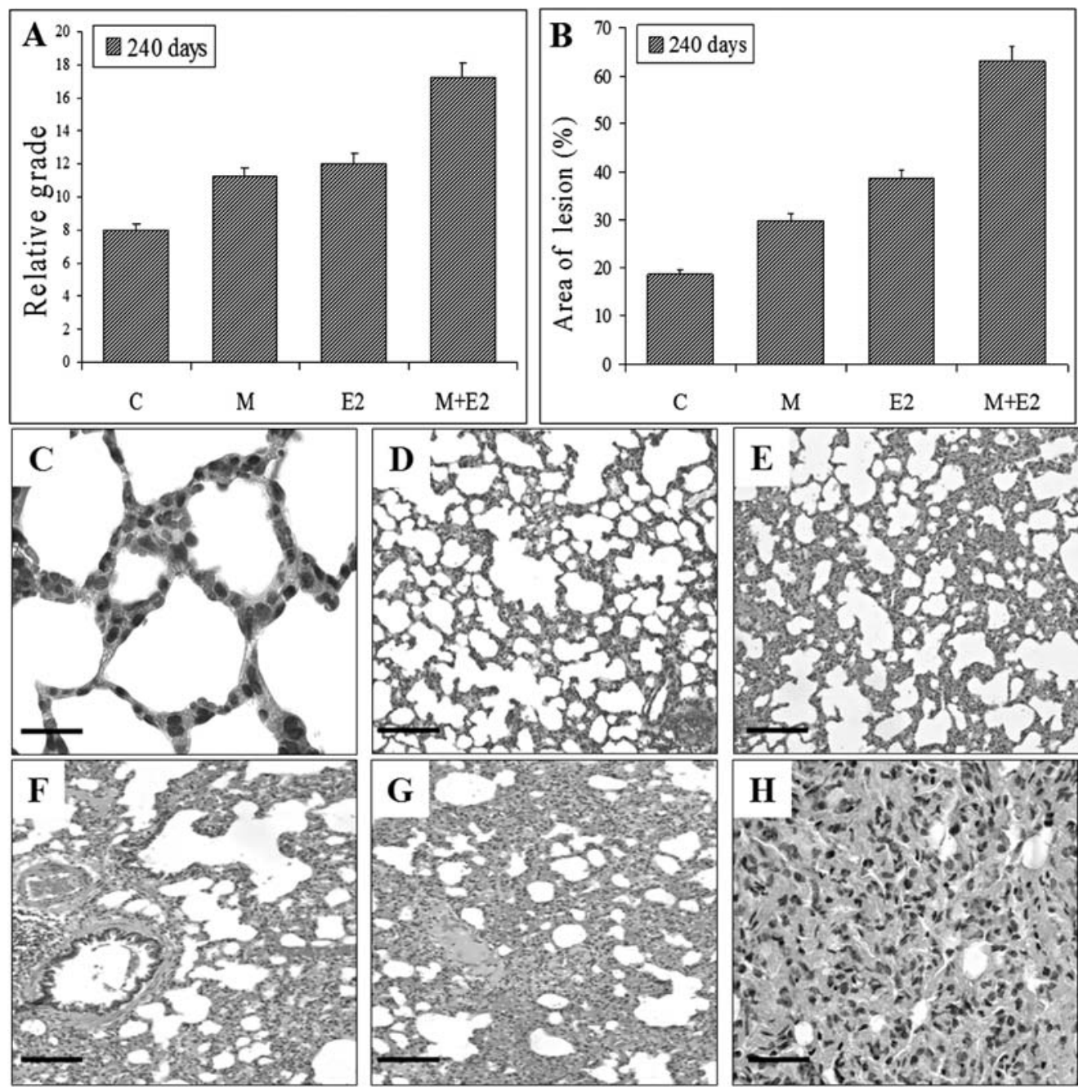

Figure 1. Bars represent the relative grade (arbitrary number) (A) and percentage of area (B) of parenchyma alveolar proliferative lesions (PAPL) in rat alveolar lungs in control and M-, E2- M+E2-treated rats for 5 days and sacrificed after 240 days. Parenchyma of alveolar lungs of control rats (C). Proliferative alveolar parenchyma lesions (PAPL) were graded in a scale from 0 to 25 . Representative images graded from 0 to 25 can be observed in D-H (D, 5; E, 10; F, 15; G, 20; and H, 25). Lung parenchyma presents cell polymorphism and nucleous of variable shapes and sizes (H). H\&E stain. Scale bars, $25 \mu \mathrm{m}(\mathrm{C}), 35 \mu \mathrm{m}(\mathrm{H})$, and $100 \mu \mathrm{m}(\mathrm{D}-\mathrm{G})$.

\section{Results}

These studies utilized an in vivo rat lung model with four experimental groups: control, the pesticide $\mathrm{M}$, the hormone E2 and combination of M plus E2. Animals were consecutive treated for 5 days commencing at 39 days of age and sacrificed at 240 days after completion of treatments. Morphometric and computational studies indicated that lung showed progressive alterations in lung parenchyma, bronchiolar epithelium and lymphatic tissue indicated by parenchyma alveolar proliferative lesions (area and grade), preneoplasias in bronchiolar epithelia (hyperplasias, squamous metaplasia, carcinoma in situ and invasive carcinoma) and lung lymphatic proliferative lesions (area). Such changes lead to tumor formation.

The results showed morphological alterations in the alveolar parenchyma in a 5-day treatment of either $\mathrm{M}$ alone, E2 alone and M+E2 sacrificed after 240 days in comparison to control. The alterations observed in the alveoli lung parenchyma of treated animals were referred as parenchyma with alveolar proliferative lesions (PAPL). Extensive area, expressed as percentage of such lesions, was significantly
$(\mathrm{P}<0.05)$ higher in $\mathrm{M}+\mathrm{E} 2$ treatments than in controls as seen in Fig. 1A and B. Furthermore, both relative grade and area of PAPL were significantly $(\mathrm{P}<0.05)$ higher in the combination of $\mathrm{M}$ and $\mathrm{E} 2$ when compared to either substance alone. However, there were no differences in such parameters when PAPL was analyzed between the two substances alone. Representative images of these alterations are seen in Fig. 1C-H. Fig. 1C shows the lung parenchyma of control animals. The PAPL of treated animals can be seen in Fig. 1D-H and consisted of cell polymorphism in size and shape with nucleus of variable shapes and sizes, characterized by hyperchromasia or anisocariosis and irregular nucleolus.

Numerous types of preneoplasias were found in the bronchiolar epithelia of rats injected with malathion and/ or estrogen for 5 days at 39-day-old and sacrificed after 240 days of treatments. The bars in Fig. 2A represent the effect of the damage found in the bronchiolar epithelium of the rat induced by M, E2 and M+E2. The percentage of bronchiolar preneoplasias found in the treated animals was 16.7, 41.6 and 41.7 in M-, E2- and M+E2-treated animals, respectively. The carcinomas in situ were only present in 

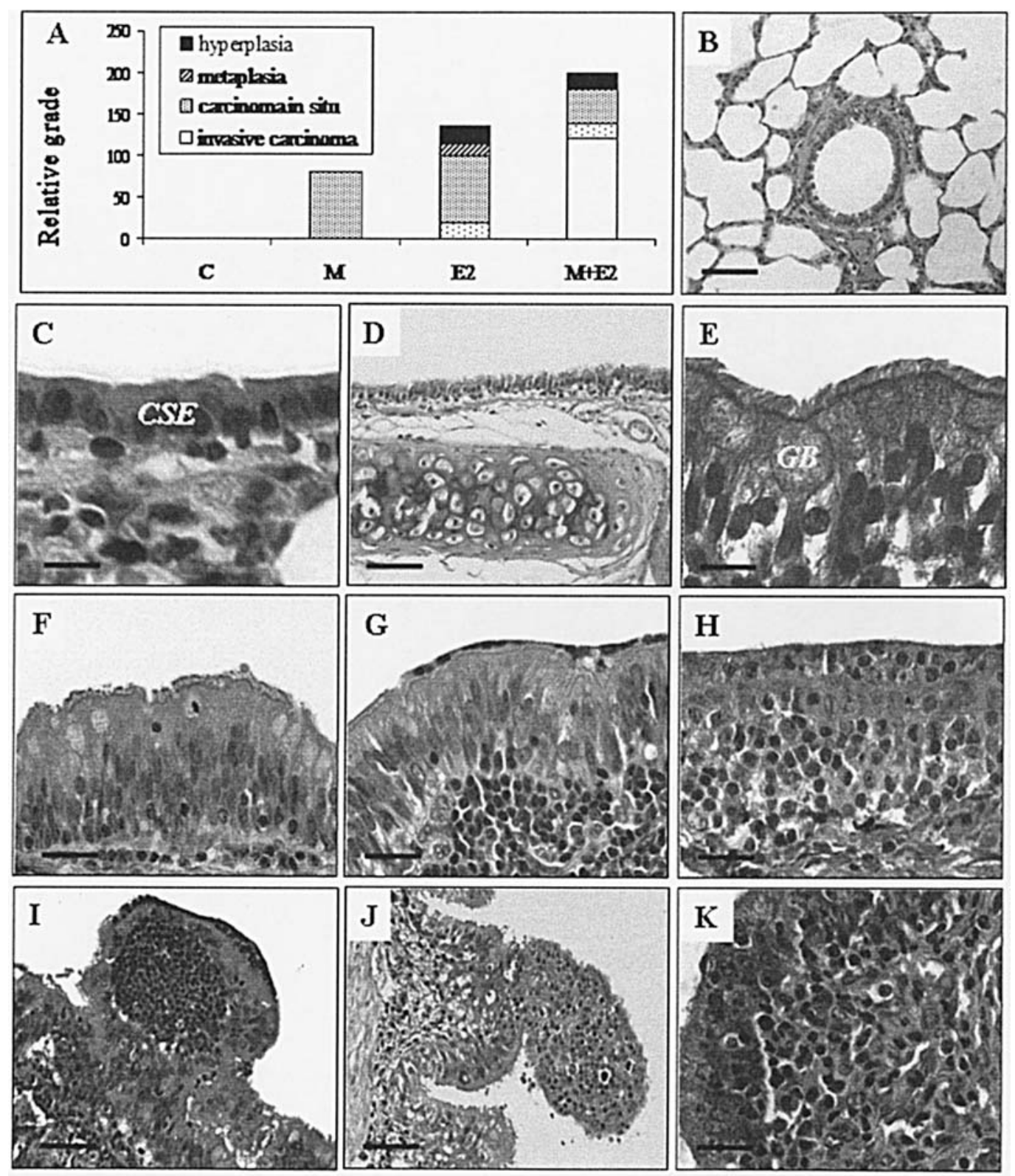

Figure 2. Bars represent the preneoplasias found in the bronchiolar epithelium of 240 days after M, E2 and M+E2 treatments (A). Normal rat bronchiolar epithelium formed by cuboidal simple epithelium at low and high magnification, respectively are shown (B and C). Normal rat bronchiolar epithelium formed by pseudostratified epithelium with goblet cells at low and higher magnification, respectively can be seen (D and E). Six types of lesions can be observed (F-K): hyperplasia (F), squamous metaplasia (G), carcinoma in situ (H), carcinoma in situ with exophilic growth called polypoids (I and J) and invasive carcinoma (K). H\&E stain. Scale bars: $10 \mu \mathrm{m}$ (C and E), $25 \mu \mathrm{m}$ (F-H and $\mathrm{K}$ ) and $50 \mu \mathrm{m}$ (B, D, I and J). Abbreviations: GC, globet cell; CSE, cuboidal simple epithelium.

M-treated animals and squamous metaplasias only in E2 treatments. A great variety of lesions were present in the E2 and $\mathrm{M}+\mathrm{E} 2$-treated rats such as hyperplasia, squamous metaplasia, carcinomas in situ and invasive carcinoma. However, invasive carcinomas were only present in groups treated with the combination of both substances. Representative images of normal bronchiolar epithelium were formed by cuboidal simple epithelium in zones near to alveoli (Fig. 2B and C) and then pseudostratified epithelium with goblet cells, typical of the respiratory system in the upper part (Fig. 2D and E). Results indicated that there was a progression in the alterations of bronchiolar epithelium induced by the effect of M, E2 and the combination of both in comparison to controls (Fig. 2F-K). The histopathological analysis of progression was characterized by four different types of preneoplasias present in the treated animals. The first lesion was described as hyperplasia characterized by an increase in number of cells (Fig. 2F); the second one as squamous metaplasia with squamous type of cells and minimum change in morphology and epithelium thickness (Fig. 2G); the third one as carcinoma in situ with numerous cell aberrations and no alterations at the level of the basal membrane, nor invasion to the stroma (Fig. $2 \mathrm{H}$ ) and with exophilic growth where cells are forming polypoids toward the lumen altering the respiratory system by changing shape and size (Fig. 2I-J); and the fourth one as invasive carcinoma, where there were a numerous cell aberrations invading to the stroma and crossing the basement membrane (Fig. 2K).

Other alterations found in the lung parenchyma of treated animals were referred as lymphatic cell aggregates (LCA). The area of LCA in M+E2-treated animals was significantly 

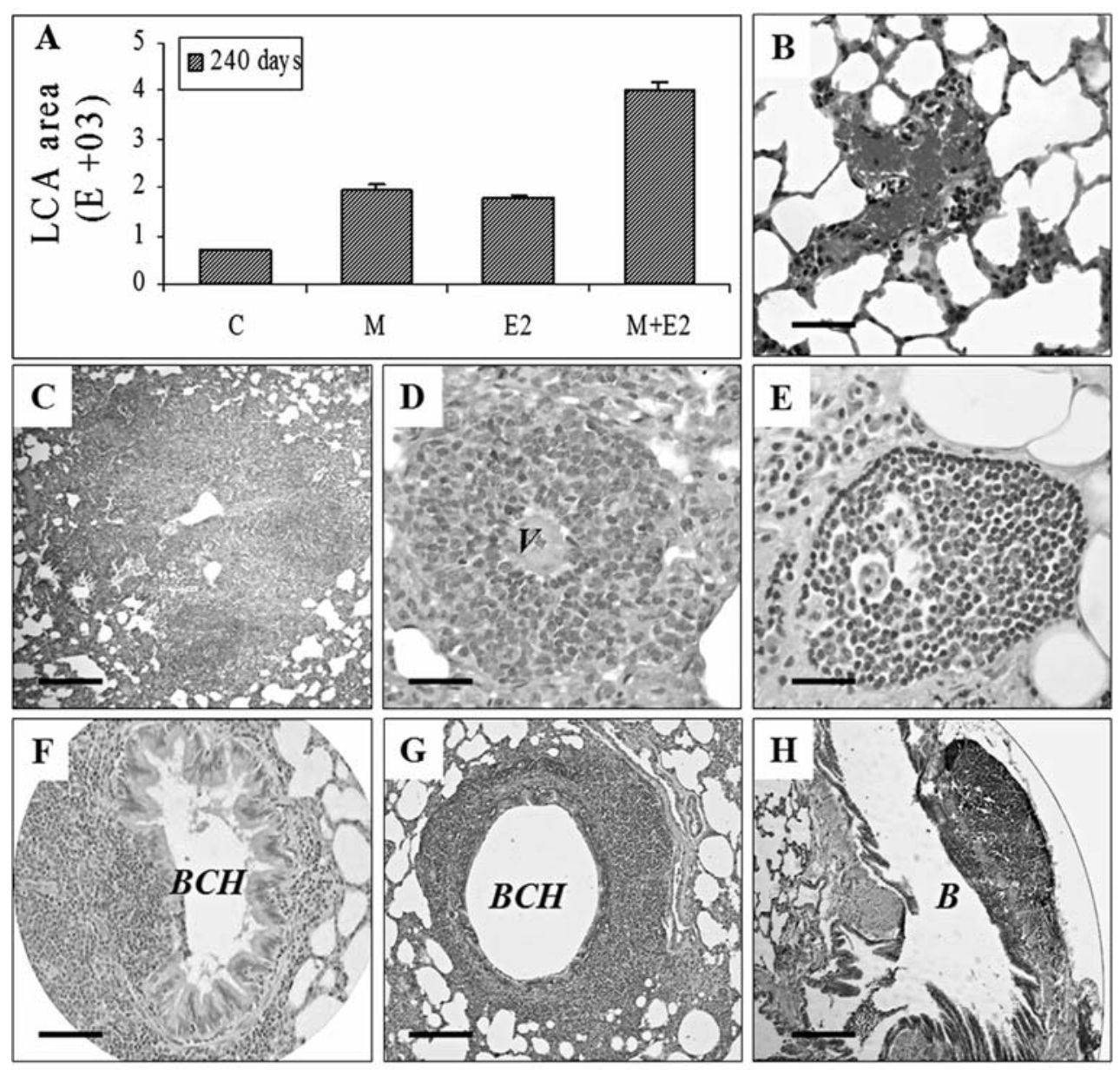

Figure 3. Bars represent the area of lymphatic cell aggregates area (LCA) found in association with parenchyma of alveolar lung of 240 days after 5 days of $\mathrm{M}, \mathrm{E} 2$ and M+E2 treatments (A). Lymphatic cells found in alveolar lung of control rats can be seen (B). LCA found in alveolar parenchyma of M+E2-treated rats (C-E) and around bronchioles of different sizes (F-H) are shown. H\&E stain. Scale bars: $35 \mu \mathrm{m}$ (B, D and E), $100 \mu \mathrm{m}(\mathrm{G}), 150 \mu \mathrm{m}(\mathrm{F})$ and $250 \mu \mathrm{m}$ $(\mathrm{C}$ and $\mathrm{H})$. Abbreviations: $\mathrm{V}$, vessel; $\mathrm{BCH}$, bronchiole; $\mathrm{BR}$, bronchi.

$(\mathrm{P}<0.05)$ higher than $\mathrm{M}$ or $\mathrm{E} 2$ alone and controls. The total area of LCA found in the lung parenchyma is represented in bars \pm standard errors (Fig. 3A). The area of LCA in $\mathrm{M}$ and E2 alone was significantly $(\mathrm{P}<0.05)$ higher than the control after 240 days of treatments. The combination of both substances was significantly $(\mathrm{P}<0.05)$ higher than the control, $\mathrm{M}$ and E2 after 240 days of treatments. However, there was no significant difference between $\mathrm{M}$ and $\mathrm{E} 2$ treatments. Fig. 3B shows representative images of normal parenchyma with few lymphatic cells in the control groups and Fig. 3C-H show LCA of treated groups. Certain structures of LCA did not present definitive shape and size (Fig. 3C and D); others, were formed by dense groups of lymphatic cells (Fig. 3E). LCA can also be seen surrounding several types of airways (Fig. 3F-H) under the effect of different treatments.

Fig. 4A show a representative tumor and B corresponds to the same tumor covered by a layer of mucilaginous substance formed in the rat lung airways by the effect of the combination of M and E2 after 240 days of a 5-day treatment. Representative images of the pathological characteristic of such tumor are seen in Fig. 4C-F. The bars in Fig. 4G represent the values of total damage induced by $\mathrm{M}, \mathrm{E} 2$ and $\mathrm{M}+\mathrm{E} 2$ in the alveolar parenchyma, bronchiolar epithelium and lymphatic tissue in comparison to control animals. Fig. 5 shows c-ErbB2 and Rho-A protein expression. Such expression increased in the presence of $\mathrm{M}+\mathrm{E}$-treated animals in comparison to control and either $\mathrm{M}$ or E2-treated animals.

\section{Discussion}

The present studies showed important morphological alterations in the lung of animals treated for 5 days with either malathion, estrogen or combination of both and examined after 240 days after treatments in comparison to controls. In the present study alterations were found as parenchyma alveolar proliferative lesions (PAPL) and preneoplasias in bronchiolar epithelium as well as LCA. It is noteworthy that proliferative alterations wer found indicating damaged PAPL in the presence of both substances, malathion and estrogen, in comparison to either substance alone. Such damage was increasing by 240 days after the 5-day treatment in comparison to controls. Such abnormalities can be suggested as a sign of progression of malignancy. However, the type of cells involved in such process was very difficult to identify by the methods used in the present study. Other reports (32) have stated similar observations in relation with this disease in recognizing normal from malignant cells due to the lack of differentiation in between alveolar cells and stroma. 

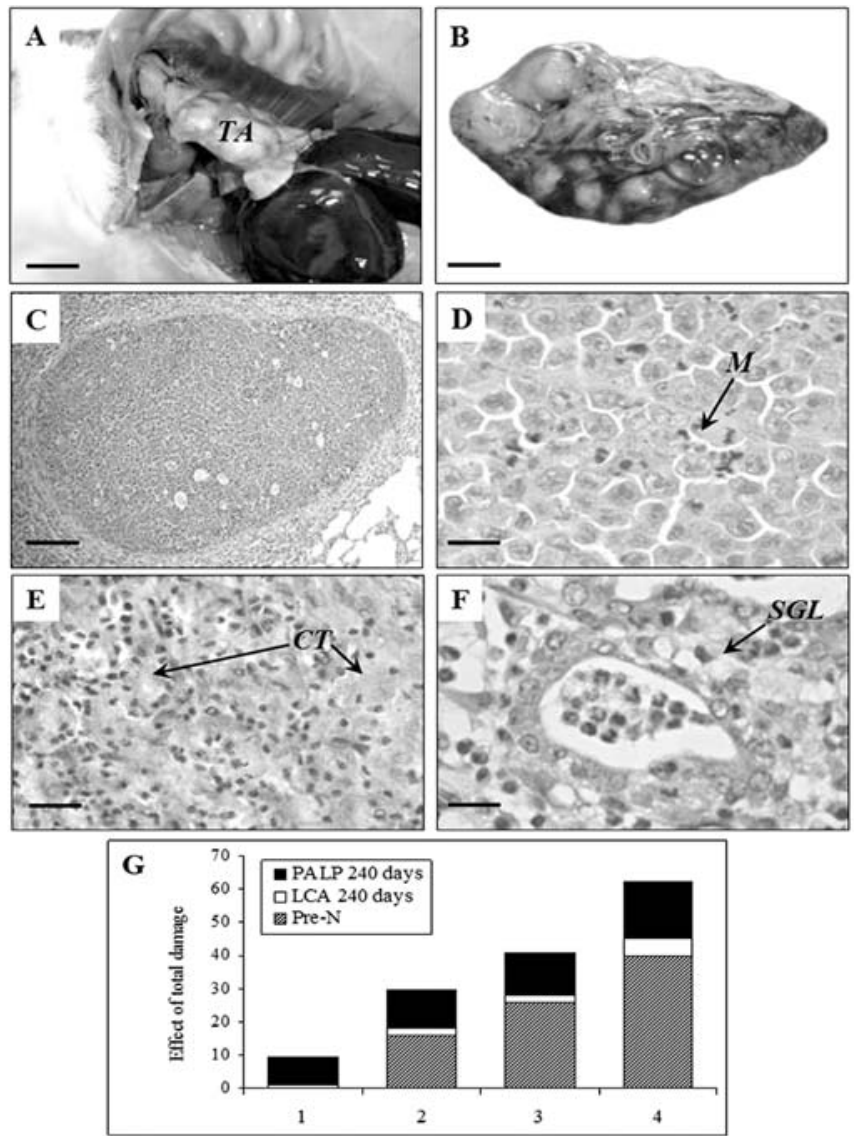

Figure 4. Rat lung tumor induced by the combination of $\mathrm{M}$ and $\mathrm{E} 2$ treatment (A) and the same tumor surrounded by a mucilaginous layer is shown (B). Cross section of lung tumor can be seen (C-F). Secretory gland-like formation can be observed in this tumor tissue $(\mathrm{F})$. Bars represent the effect of the total damage induced in the rat lung by the effect of M, E2 and M+E2 treatments for 5 days and sacrificed after 240 days that include alveolar parenchyma (area of PAPL), bronchiolar epithelium (relative grade of preneoplasias) and lymphatic tissue (area of LCA) (G). H\&E stain. Scale bars, $15 \mu \mathrm{m}$ (D and F), $50 \mu \mathrm{m}$ (E), $100 \mu \mathrm{m}$ (C), $5 \mathrm{~mm}$ (B) and $15 \mathrm{~mm}$ (A). Abbreviation: TA, tumor in airway; $\mathrm{M}$, mitosis; CT, connective tissue; SGL, secretory gland-like.

Histopathological analysis of the bronchiolar tissues of treated animals demonstrated four different types of preneoplasias in treated animals. The types of lesions were not present in all the samples at the same time or treatment. The carcinomas in situ were the predominant lesions in the bronchiolar epithelium of malathion-treated animals. Other studies (33) have demonstrated extensive damage in the alveolar epithelium in the malathion-treated rats but not in the bronchiolar epithelium. The present results showed that estrogen alone and malathion plus estrogen induced numerous types of lesions such as hyperplasia, squamous metaplasia, carcinomas in situ and invasive carcinoma. The percentage of lesions was similar among the two groups. However, the invasive carcinoma was only present in malathion- and estrogen-treated groups. These results seem to suggest a greater possibility to develop lung cancer when high amount of preneoplasias, especially invasive carcinoma, are subjected to the effect of the combination of these two substances. In agreement with these findings, others $(34,35)$ have previously reported that a high degree of dysplasias and carcinomas in situ, well known pre-
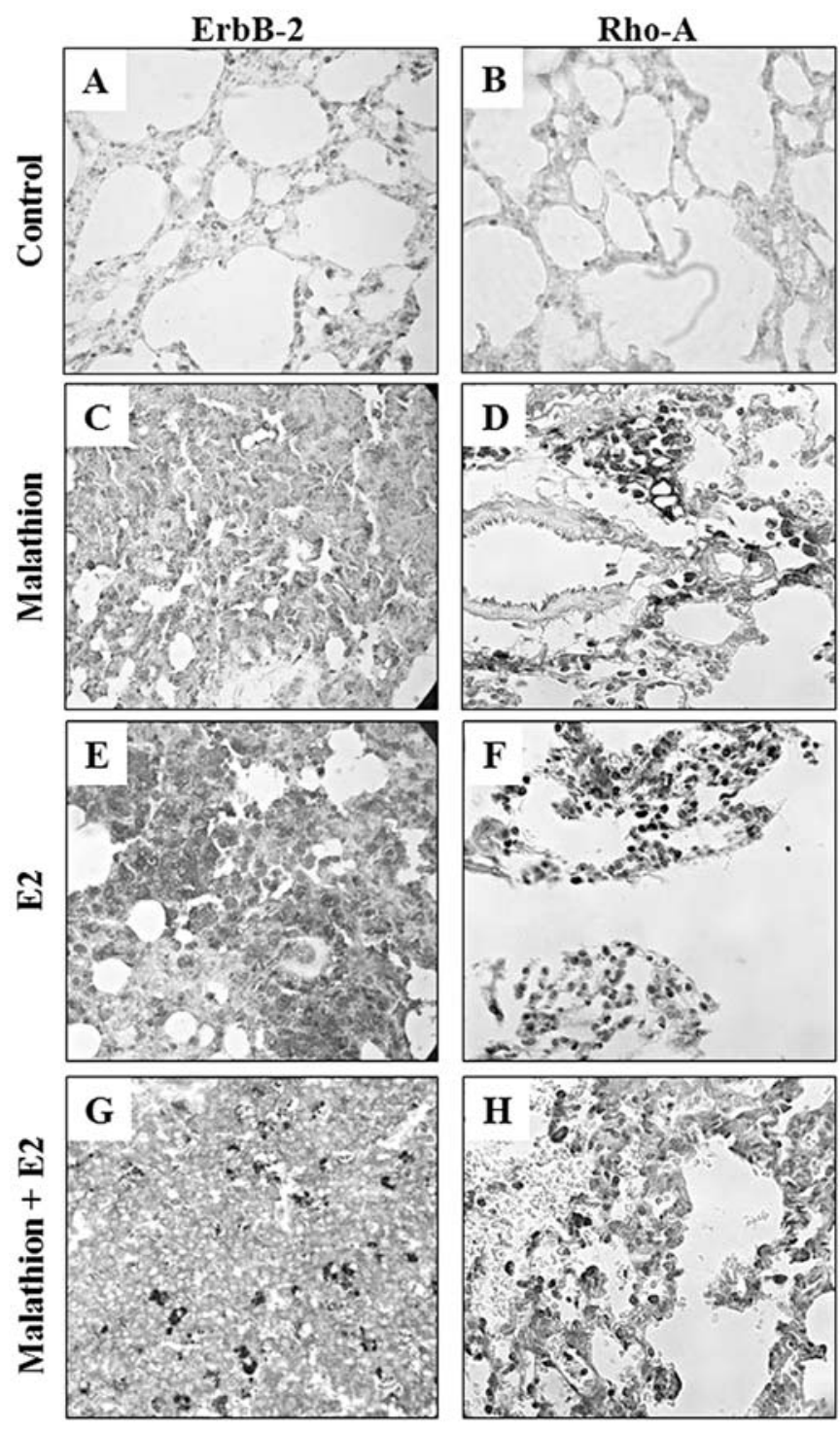

Figure 5. Immunochemical imaging of c-ErbB2 and Rho-A protein expression in control and malathion-, estrogen (E2)-malathion+E2-treated rats for 5 days and sacrificed after 240 days (A-H).

malignant lesions, were associated with a significant increase in the risk of developing lung carcinomas. Wilbur and Franklin (32) considered that squamous metaplasia or dysplasia was frequently associated with invasive carcinoma type.

The presence of lymphoid tissue in control animals observed in the present study is common in other normal species such as rats, rabbits, and sheep $(36,37)$. Increased lymphoid cell aggregates were found in control rats of 240 days in comparison to control rats of 30 and 124 days according to other reports (38) where it was recognized as a normal feature of an increase of lymphoid cell aggregates in the old rats from 32 to 40 weeks of age. The lymphatic structures found in control rats corresponded to bronchioleassociated lymphoid tissue (BALT) that is considered to play an important role in the local and systemic immune responses of the lung (39). According to this study, BALT was found along the bifurcations of the upper bronchi directly beneath the epithelium and generally lying between an artery and a bronchus (40) but not in small airways. 
The present results showed a mixed pattern in lymphoid tissue that varied from multifocal proliferations in the airway walls, solitary mass or nodule and lymphoid multifocal or diffuse lymphoid hyperplasia of BALT, in accordance with other authors (41). Lymphoid cell aggregates were observed around the large and small airways in treated rats. Previously $(42,43)$ similar small airways structures were found and named inducible BALT (iBALT) in order to distinguish them from normal BALT structures in large airways. Other works had shown that accumulation of lymphoid aggregates may prepare the background for the development of BALT lymphoma (44). It seems from the present study that the animals treated with combination of the pesticide malathion and estrogen may present a higher risk to form malignant lymphomas than malathion or estrogen alone. Human studies suggest that elevated risk of non-Hodgkin's lymphoma and leukemia among farmers may be associated with exposure to malathion and other agricultural chemicals (45-47). The distinction between well differentiated lymphocytic lymphoma and lymphoid hyperplasia may be extremely difficult $(48,49)$ since there is considerable overlap between them because the slight degree of cytologic atypia of the lymphoid cells and the mixture of normal inflammatory cells.

In these studies it was shown that malathion alone was able to develop proliferative lesions in alveolar parenchyma, bronchiolar epithelium and lymphatic tissue. It has been reported $(20,50)$ that there was no clear evidence between the association of lung tumor incidence and the administration of malathion to Osborne-Mendel rats or $\mathrm{B} 6 \mathrm{C} 3 \mathrm{~F} 1$ mice. The only induction of lung tumors with malathion comes from the administration of this pesticide to Sprague-Dawley rats where a higher incidence and shorter induction time in tumor formation was found in combination with dimethylbenzanthracene (DMBA) than DMBA alone (20,51).

This work indicated that lung is a hormone responsive tissue confirming the role of estrogen in lung tumorigenesis reported by others (52). Estrogen has been considered a cancer promoter in woman lung cancer (53). Such work showed that estrogen induced alterations in lung tissues. Other authors (54) showed an increased risk of lung cancer in women receiving hormone replacement therapy.

The alterations in lung tissue induced by the exposure to malathion and estrogen shown in these studies seem to indicate an increased risk of lung cancer. Occupational exposures to pesticides appear to have adverse effects on female reproduction (11). Given the multi-factorial etiology of lung cancer, multiple interactions among risk factors (exogenous and endogenous) may have substantial consequences for lung cancer risk (1). Thus, exogenous factors such as cigarette smoke and asbestos exposure can have an impact on the lung cancer risk (55). Another example to be considered is the positive interaction between estrogen replacement therapy and smoking demonstrated by the development of lung adenocarcinoma in women $(16,56,57)$. It appears that the higher circulating levels of estrogen in premenopausal women when compared to men make women particularly susceptible to the carcinogenic influence of tobacco smoke.

Histopathologic findings cannot adequately predict for self disease progression, so there is a need to identify molecular factors that serve this purpose. Because the ErbB2 receptors play an important role in lung cancer progression and Rho-A is a potential prognostic factor in lung cancer to detect metastasis process, the protein expression of ErbB2 and Rho-A was analyzed. ErbB2 protein expression was higher in malathion plus E2-treated cells than control. Other authors (58) found that there was a co-expression of EGFR and ErbB2 protein in patients with metastasis in 119 cases of primary human lung adenocarcinoma. Therefore, the ErbB2 family of receptors has been evaluated for the potential prognostic role in lung cancer, for which therapeutic approaches do exist $(59,60)$. Rho-A protein expression was higher in malathion plus E2-treated cells than control. Members of the Rho family of small GTPases control the organization of the actin/myosin cytoskeleton, and thus play significant roles in metastasis $(24,25)$. Cells transformed with activated Rho-A also exhibit metastatic characteristics in animal models (61). Numerous studies indicate that Rho family members also contribute to the transformed phenotype of cancer cells $(62,63)$. Studies have demonstrated greater expression of the small GTPase Rho-A in SCLC cell lines than in NSCLC cell lines suggesting differences in the expression or activity of Rho-A between these forms of lung cancer (64).

In conclusion, endogenous and environmental risk factors are thought to be common in multifactorial disorders, including cancer, thus malathion, an organophosphorous compound, and estrogen, a hormone present in the circulatory system of women, induced proliferative lesions in alveolar parenchyma, bronchiolar epithelia and lymphatic tissue modifying the normal morphological pattern of the lung. Molecular findings demonstrate that the phenotypical alterations in the lung were due to malathion and/or estrogen treatments suggesting an alternative therapeutic strategy to detect lung cancer in women exposed to environmental pesticides. Thus, it can be concluded that the combination of malathion and estrogen promoted preneoplastic lesions and then tumor formation. This new in vivo study can be very useful to understand the morphological changes associated to molecular alterations that occur in lung cancer and then take preventive approaches to reduce the overall mortality associated with lung cancer not only in women exposed to hormonal changes during her life but in men working in pesticide environment. It will be important to develop strategies to protect agricultural workers and bystanders, both with a high risk for lung cancer.

\section{Acknowledgements}

We sincerely thank Dr Clifford Welsch for his valuable criticism and Danissa Barahona for her secretarial assistance. Support given by FONDECYT \#1040300 - \#1080482 (GMC) is greatly appreciated.

\section{References}

1. Alberg AJ and Samet JM: Epidemiology of lung cancer. Chest 123: S21-S49, 2003.

2. Damber LA and Larsson LG: Occupation and male lung cancer: a case-control study in northern Sweden. Br J Ind Med 44: 446-453, 1987.

3. Fenske RA, Lu C, Barr D and Needham L: Children's exposure to chlorpyrifos and parathion in an agricultural community in central Washington State. Environ Health Perspect 110: 549-553, 2002 . 
4. Koch D, Lu C, Fisker-Andersen J, Jolley L and Fenske RA: Temporal association of children's pesticide exposure and agricultural spraying: report of a longitudinal biological monitoring study. Environ Health Perspect 110: 829-833, 2002.

5. Wilhoit L, Davidson N, Supkoff D, et al: Pesticide use analysis and trends from 1991 to 1996. Environmental Protection Agency, Sacramento, CA, 1999.

6. Berkowitz GS, Obel J, Deych E, et al: Exposure to indoor pesticides during pregnancy in a multiethnic, urban cohort. Environ Health Perspect 111: 79-84, 2003.

7. CDC (Centers for Disease Control and Prevention): Second National Report on Human Exposure to Environmental Chemicals. NCEH Publication No. 03-0022. Atlanta, GA, 2003.

8. Lu C, Knutson DE, Fisker-Andersen J and Fenske RA: Biological monitoring survey of organophosphorus pesticide exposure among preschool children in the Seattle metropolitan area. Environ Health Perspect 109: 299-303, 2001.

9. Weisenburger DD: Human health effects of agrichemical use. Hum Pathol 24: 571-576, 1993.

10. Whyatt RM, Camann DE, Kinney PL, et al: Residential pesticide use during pregnancy among a cohort of urban minority women. Environ Health Perspect 110: 507-514, 2002.

11. Bretveld RW, Thomas CM, Scheepers PT, Zielhuis GA and Roeleveld N: Pesticide exposure: the hormonal function of the female reproductive system disrupted? Reprod Biol Endocrinol 4: 30, 2006.

12. Thomas L, Doyle LA and Edelman MJ: Lung cancer in women emerging differences in epidemiology, biology and therapy. Chest 128: 370-381, 2005.

13. Calaf G and Hei TK: Establishment of a radiation- and estrogen induced breast cancer. Carcinogenesis 21: 769-776, 2000.

14. Calaf G: Susceptibility of breast epithelial cells in vitro to hormones and drugs. Int J Oncol 28: 285-295, 2006

15. Henderson BE, Ross RK, Pike MC and Casagrande JT: Endogenous hormones as a major factor in human cancer. Cancer Res 42: 3232-3239, 1982.

16. Taioli E and Wynder EL: Endocrine factors and adenocarcinoma of the lung in women. J Natl Cancer Inst 86: 869-870, 1994

17. Gretz JE, Anderson AO and Shaw S: Cords, channels, corridors and conduits: critical architectural elements facilitating cell interactions in the lymph node cortex. Immunol Rev 156: 11-24, 1997.

18. Bienenstock J, Johnston N and Perey DY: Bronchial lymphoid tissue: I. Morphologic characteristics. Lab Invest 28: 686-692, 1973.

19. Travis WD and Galvin JR: Non-neoplastic pulmonary lymphoid lesions. Thorax 56: 964-971, 2001.

20. Alimandi M, Romano A, Curia MC, et al: Cooperative signalling of ErbB3 and ErbB2 in neoplastic transformation and human mammary carcinomas. Oncogene 10: 1813-1821, 1995.

21. Yu D, Wang SS, Dulski KM, Tsai CM, Nicolson GL and Hung MC: c-erbB-2/neu overexpression enhances metastatic potential of human lung cancer cells by induction of metastasisassociated properties. Cancer Res 54: 3260-3266, 1994.

22. Klapper LN, Kirschbaum MH, Sela M and Yarden Y: Biochemical and clinical implications of the ErbB/HER signaling network of growth factor receptors. Adv Cancer Res 77: 25-79, 2000.

23. Graus-Porta D, Beerli RR, Daly JM and Haynes NE: ErbB-2, the preferred heterodimerization partner of all ErbB receptors, is a mediator of lateral signaling. EMBO J 16: 1647-1655, 1997.

24. Kaibuchi K, Kuroda S and Amano M: Regulation of the cytoskeleton and cell adhesion by the Rho family GTPases in mammalian cells. Annu Rev Biochem 68: 459-486, 1999.

25. Michiels F and Collard JG: Rho-like GTPases: their role in cell adhesion and invasion. Biochem Soc Symp 65: 125-146, 1999.

26. National Cancer Institute: Bioassay of malathion for possible carcinogenicity. Technical report series No. 24. DHEW Publication No. (NIH) 78-824, 1978.

27. Institute of Animal Laboratory Resources: Guide for the Care and Use of Laboratory Animals. National Academy Press, Washington, DC, 1996.

28. Cabello G, Valenzuela M, Vilaxam A, Durán V, Rudolph I, Hrepic N and Calaf GM: A rat mammary tumor model induced by the organophosphorous pesticides parathion and malathion, possibly through acetylcholinesterase inhibition. Environ Health Perspect 109: 471-479, 2001.

29. Breuer RH, Pasic A, Smit EF et al: The natural course of preneoplastic lesions in bronchial epithelium. Clin Cancer Res 11: 537-543, 2005.
30. Brambilla E, Travis WD, Colby TV, Corrin B and Shimosato Y The new WHO classification of lung tumours. Eur Respir J 18: 1059-1068, 2001.

31. Colby TV, Wistuba II and Gazdar A: Precursors to pulmonary neoplasia. Adv Anat Pathol 5: 205-215, 1998.

32. Wilbur A and Franklin MD: Diagnosis of lung cancer: pathology of invasive and preinvasive neoplasia. Chest 117: 80-89, 2000 .

33. Dinsdale D, Verschoyle RD and Ingham JE: Ultrastructural changes in rat Clara cells induced by a single dose of O, S, Strimethylphosphorodithioate. Arch Toxicol 56: 59-65, 1984.

34. Frost JK, Ball WC Jr, Levin ML, et al: Sputum cytopathology: use and potential in monitoring the workplace environment by screening for biological effects of exposure. J Occup Med 28: 692-703, 1986.

35. Venmans BJ, van Boxem TJ, Smit EF, Postmus PE and Sutedja TG: Outcome of bronchial carcinoma in situ. Chest 117: 1572-1576, 2000.

36. Swigris JJ, Berry GJ, Raffin TA and Kuschner WG: Lymphoid interstitial pneumonia: a narrative review. Chest 122: 2150-2164, 2002.

37. Pabst $\mathrm{R}$ and Gehrke I: Is the bronchus associated lymphoid tissue (BALT) an integral structure of the lung in normal mammals, including humans? Am J Respir Cell Mol Biol 3: 131-135, 1990.

38. Tango M, Suzuki E, Gejyo F and Ushiki T: The presence of specialized epithelial cells on the bronchus-associated lymphoid tissue (BALT) in the mouse. Arch Histol Cytol 63: 81-89, 2000.

39. Iwata M and Sato A: Morphological and immunohistochemical studies of the lungs and bronchus-associated lymphoid tissue in a rat model of chronic pulmonary infection with pseudomonas aeruginosa. Infect Immun 59: 1514-1520, 1991.

40. Sminia T, van der Brugge-Gamelkoorn GJ and Jeurissen SH: Structure and function of bronchus-associated lymphoid tissue (BALT). Crit Rev Immunol 9: 119-150, 1989.

41. Koss MN: Pulmonary lymphoid disorders. Semin Diagn Pathol 12: 158-171, 1995.

42. Moyron-Quiroz JE, Rancel-Moreno J, Kusser K, et al: Role of inducible bronchus associated lymphoid tissue (iBALT) in respiratory immunity. Nat Med 10: 927-934, 2004.

43. Rangel-Moreno J, Hartson L, Navarro C, Gaxiola M, Selman M and Randall TD: Inducible bronchus-associated lymphoid tissue (iBALT) in patients with pulmonary complications of rheumatoid arthritis. J Clin Invest 116: 3183-3194, 2006.

44. Parsonnet J: Molecular mechanisms for inflammation-promoted pathogenesis of cancer - The Sixteen International Symposium of the Sapporo Cancer Seminar. Cancer Res 57: 3620-3624, 1997

45. Brown LM, Blair A, Gibson R, Everett GD, Cantor KP, Schuman LM, Burmeister LF, van Lier SF and Dick F: Pesticide exposures and other agricultural risk factors for leukemia among men in Iowa and Minnesota. Cancer Res 50: 6585-6591, 1990.

46. Cantor KP, Blair A, Everett G, et al: Pesticides and other agricultural risk factors for non-Hodgkin's lymphoma among men in Iowa and Minnesota. Cancer Res 52: 2447-2455, 1992.

47. McDuffie HH, Pahwa P, MacLaughlin JR, et al: Non-Hodgkin's lymphoma and specific pesticide exposures in men: crossCanada study of pesticides and health. Cancer Epidemiol Biomarkers Prev 10: 1155-1153, 2001.

48. Aleric I, Tentor D and Jakic-Razumovic J: Multiple lung infiltrates. Respiration 71: 101-103, 2004.

49. Ahmed S, Siddiqui AK and Rai KR: Low-grade B-cell bronchial associated lymphoid tissue (BALT) lymphoma. Cancer Invest 20: 1059-1068, 2002.

50. Hazleton LW and Holland EG: Toxicity of malathon: summary of mammalian investigations. AMA Arch Ind Hgy Occup Med 8: 399-405, 1953.

51. Okey AB: Dimethylbenzanthracene-induced mammary tumors in rats: inhibition by DDT. Life Sci I 11: 833-843, 1972.

52. Xu J and Li Q: Review of the in vivo functions of the p160 steroid receptor coactivator family. Mol Endocrinol 17: 1681-1692, 2003.

53. Stabile LP, Davis AL, Gubish CT, et al: Human non-small cell lung tumors and cells derived from normal lung express both estrogen receptor alpha and beta and show biological responses to estrogen. Cancer Res 62: 2141-2150, 2002.

54. Adami HO, Persson I, Hoover R, Schairer C and Bergkvist L: Risk of cancer in women receiving hormone replacement therapy. Int J Cancer 44: 833-839, 1989. 
55. Saracci R and Boffetta P: Interactions of tobacco smoking and other causes of lung cancer. In: Epidemiology of Lung Cancer: Lung Cancer in Health and Desease. Samet JM (ed.) Marcel Dekker, New York, NY, pp465-493, 1994.

56. Hershberger PA, Vasquez AC, Kanterewicz BL and Siegfried JM and Nichols M: Regulation of endogenous gene expression in human non-small cell lung cancer cells by estrogen receptor ligands. Cancer Res 65: 1598-1605, 2005.

57. Calaf G and Hei TK: Oncoprotein expressions in human breast epithelial cells transformed by high-LET radiation. Int J Radiat Biol 77: 31-40, 2001

58. Tateishi M, Ishida T, Kohdono S, Hamatake M, Fukuyama Y and Sugimachi K: Prognostic influence of the co-expression of epidermal growth factor receptor and c-erbB-2 protein in human lung adenocarcinoma. Surg Oncol 3: 109-113, 1994.

59. Onn A, Correa A, Gilcrease M, et al: Overexpression of epidermal growth factor receptor and HER2-neu protein is a predictor of poor outcome in patients with stage I non-small cell lung cancer. Clin Cancer Res 10: 136-143, 2004.
60. Brabender J, Danenberg K, Metzger R, et al: Epidermal growth factor receptor and her2-neu mrna expression in non-small cell lung cancer is correlated with survival. Clin Cancer Res 7: $1850-1855,2001$.

61. Del Peso L, Hernandez-Alcoceba R, Embade N, Carnero A, Esteve P, Paje C and Lacal JC: Rho proteins induce metastático properties in vivo. Oncogene 15: 3057-3067, 1997.

62. Fort P: Small GTPases of the Rho family and cell transformation. Prog Mol Subcell Biol 22: 159-181, 1999.

63. Zohn IM, Campbell SL, Khosravi-Far R, Rossman KL and Der CJ: Rho family proteins and Ras transformation: the RHOad less traveled gets congested. Oncogene 17: 1415-1438, 1999.

64. Varker KA, Phelps SH, King MM and Williams CL: The small GTPase RhoA has greater expression in small cell lung carcinoma than in non-small cell lung carcinoma and contributes to their unique morphologies. Int J Oncol 22: 671-681, 2003. 